Chike Obi , Claudio Achebe

\title{
Nature Reviews Endocrinology: Acromegaly
}

Department of production animal medicine and Medical sciences, Nigeria

${ }^{*}$ Corresponding Author : Chike Obi, Department of production animal medicine and Medical sciences, Nigeria. E-mail: chike.obi12@gmail.com

\author{
Received date: January 02, 2018;Accepted date : January 20, 2018; Published date: February 05, 2018. \\ Citation for this Article : Chike Obi , Claudio Achebe, Nature Reviews Endocrinology:Acromegaly. J. Endocrinology and Disorders. \\ Doi: $10.31579 / 2640-1045 / 019$
}

Copyright : (c) 2018 Chike Obi.This is an open-access article distributed under the terms of the Creative Commons Attribution License, which permits unrestricted use, distribution, and reproduction in any medium, provided the original author and source are credited.

\begin{abstract}
Acromegaly is a rare disease most often caused by the prolonged secretion of excess growth hormone from a pituitary adenoma. The disease is associated with multiple significant comorbidities and increased mortality. The delay to diagnosis is often long. This may be because of low disease awareness among health care professionals, the insidious onset of differentiating features, and because patients are likely to present with complaints typical of other conditions more frequently seen in primary care. Early identification of acromegaly facilitates prompt treatment initiation and may minimize the permanent effects of excess growth hormone. The primary treatment for many patients will be pituitary surgery, although not all patients will be eligible for surgery or achieve a surgical cure.

Keywords

Acromegaly; Diagnosis, Treatment; Quality Of Life; Convenience
\end{abstract}

\section{Introduction}

Acromegaly results from the hypersecretion of growth hormone (GH), usually by a pituitary tumor. 1 The average age at diagnosis is 40 years, with an equal number of men and women affected. The disease is uncommon, although the exact prevalence is unclear; a recent review noted estimates of between 40 and 130 cases per million adults. 2 By comparison, in 2011, diabetes was estimated to affect $8.3 \%$ of adults (ie, 83,000 cases/million) aged over 20 years worldwide. 3 A confirmed diagnosis of acromegaly commonly takes several years, 4 leading to potentially serious consequences for patients' health and well-being. These delays may be due partly to the fact that many of the clinical features of acromegaly are nonspecific and similar to those seen with other conditions more often seen in primary care, such as hypertension or diabetes. The delay may also be because of the insidious onset of differentiating symptoms, such as acral enlargement.

\section{Pathophysiology and clinical presentation}

The pituitary gland, located just below the base of the brain is responsible for secreting many hormones, including $\mathrm{GH}$, which is regulated via sophisticated feedback pathways.1 Acromegaly is most often due to the presence of a (generally benign) tumor in the pituitary gland.1 The tumor mass, depending on its size and location, may cause problems, such as vision loss due to compression of the optic chiasm. However, the tumor also secretes excess GH, resulting in increased secretion of insulin-like growth factor 1 (IGF-1). Excess GH and IGF-1 over a prolonged period are responsible for multiple significant comorbidities, including cardiovascular complications, cerebrovascular events, gonadal dysfunction, impaired glucose tolerance and diabetes, sleep apnea, impaired respiratory function, colonic neoplasms, and bone and joint diseases5,6,8,9 $\mathrm{GH}$ excess is also associated with an increased mortality rate, which is further elevated if comorbidities, particularly cardiovascular disease, are present.10 Specifically, mortality rates in untreated acromegaly are two to three times higher than those for the general population. Thus, early diagnosis and biochemical normalization are crucial in minimizing the permanent and life-limiting effects of excess $\mathrm{GH}$.

\section{Diagnosing acromegaly}

Patients with longstanding disease commonly present at advanced stages with striking physical characteristics (eg, enlarged hands, feet, lips and tongue; prominent supraorbital ridges; and lower jaw protrusion) However, the onset of physical changes is insidious and patients are unlikely to present with complaints relating directly to these distinguishing signs of acromegaly;5 rather, they are more likely to present with complaints typical of other conditions (eg, cardiovascular disease, diabetes, hypertension, and sleep apnea) more commonly seen in primary care.

\section{Treatment options}

The interrelated aims of treatment for acromegaly are to: control/reduce tumor size, normalize GH and IGF-1 levels, and improve comorbidities.57 These may all contribute to reductions in the mortality rate. Patients may receive as many as three different treatment modalities in an attempt to achieve these aims. Pituitary surgery is generally recommended as the primary treatment in patients with microadenomas (tumors $<1 \mathrm{~cm}$ ) and also in patients with macroadenomas (tumors $>1 \mathrm{~cm}$ ) that are associated with local mass effects or are enclosed and potentially curable surgically.5,7 Although transsphenoidal surgery, in which microsurgical instruments are passed through the nasal passage using either a microscope or an endoscope, is considered the safest route, there are nonetheless risks to be considered. These risks include, but are not limited to, bleeding, cerebrospinal fluid leaks, and pituitary gland damage with postoperative hormonal insufficiency. The severity of these risks and the success of the operation are, however, highly dependent on the neurosurgeon's experience. Even with an experienced neurosurgeon, not all patients achieve a surgical cure. In a study documenting surgical outcomes from one center over a 19-year period, a cure (postoperative normalization of basal GH level, suppression of GH level to $<1 \mathrm{ng} / \mathrm{mL}$ during an oral glucose load, and normalization of IGF-1 Level) was apparent in $57 \%$ of 506 patients undergoing primary transsphenoidal surgery.13 Within this patient cohort, success rates were highest for those with microadenomas $(75 \%)$ or intrasellar macroadenomas (ie, macroadenomas localized within the immediate bony space) $(74 \%)$. 


\section{Conclusion}

Acromegaly is a serious condition, associated with multiple comorbidities and increased mortality. The delay to diagnosis is often long. This is probably due to low disease awareness among health care professionals, the insidious onset of differentiating features, and because patients are likely to present with complaints typical of other conditions more frequently seen in primary care. Early identification of the signs and symptoms of the disease by health care professionals knowledgeable about acromegaly may help to mitigate this delay. Treatment can then be initiated promptly, with the potential to reduce mortality.

\section{References}

1. Melmed S. Medical progress: acromegaly. N Engl J Med. 2006;355(24):2558-2573.

2. Chanson P, Salenave S, Kamenicky P, Cazabat L,. Pituitary tumours: acromegaly. Best Pract Res Clin Endocrinol Metab. 2009;23(5):555-574.

3. International Diabetes Federation (IDF) IDF Diabetes Atlas. 5th ed. Brussels: IDF; 2011.

4. Nachtigall L, Delgado A, Swearingen B, Lee H, Zerikly R,and Klibanski A et al.. Changing patterns in diagnosis and therapy of acromegaly over two decades. J Clin Endocrinol Metab. 2008;93(6):2035-2041https://doi.org/10.1210/jc.2007-2149.

5. Katznelson L, Atkinson JL, Cook DM, Ezzat SZ, Hamrahian AH, Miller KK American Association of Clinical Endocrinologists. American Association of Clinical Endocrinologists medical guidelines for clinical practice for the diagnosis and treatment of acromegaly - 2011 update. Endocr Pract. 2011;17( Suppl 4):144.

6. Giustina A, Chanson P, Bronstein MD, et al. Acromegaly Consensus Group. A consensus on criteria for cure of acromegaly. J Clin Endocrinol Metab. 2010;95(7):31413148.https://doi.org/10.1210/jc.2009-2670

7. Melmed S, Colao A, Barkan A, et al. Acromegaly Consensus Group. Guidelines for acromegaly management: an update. J Clin Endocrinol Metab. 2009;94(5):1509-1517https://doi.org/ 10.1210/jc.2002-011841.
8. Davi' MV, Dalle Carbonare L, Giustina A, et al. Sleep apnoea syndrome is highly prevalent in acromegaly and only partially reversible after biochemical control of the disease. Eur J Endocrinol. 2008;159(5):533-540.https://doi.org/10.1530/EJE-

9. Rokkas T, Pistiolas D, Sechopoulos P, Margantinis G, and Koukoulis G. et al. Risk of colorectal neoplasm in patients with acromegaly: a meta-analysis. World J Gastroenterol. 2008;14(22):3484-3489.doi: [10.3748/wjg.14.3484]

10. Sherlock M, Ayuk J, Tomlinson JW, et al. Mortality in patients with pituitary disease. Endocr Rev. 2010;31(3):301-342. https://doi.org/10.1210/jc.2003-031584

11. Drange MR, Fram NR, Herman-Bonert V, Melmed S. Pituitary tumor registry: a novel clinical resource. J Clin Endocrinol Metab. 2000;85(1):168-174.https://doi.org/10.1210/jcem.85.1.6309

12. Freda PU, Reyes CM, Nuruzzaman AT, Sundeen RE, Bruce JN. Basal and glucose-suppressed GH levels less than 1 microg/L in newly diagnosed acromegaly. Pituitary. 2003;6(4):175-180.

13. Nomikos P, Buchfelder M, Fahlbusch R. The outcome of surgery in 668 patients with acromegaly using current criteria of biochemical "cure." Eur J Endocrinol. 2005;152(3):379387.https://doi.org/10.1530/eje.1.01863

14. Ipsen Somatuline ${ }^{\circledR}$ Depot [prescribing information] Silver Spring, MD: US Food and Drug Administration (FDA); 2011. [Accessed September 28, 2012]. Available from:

15. Novartis Sandostatin ${ }^{\circledR}$ LAR Depot [prescribing information] Silver Spring, MD: FDA; 2011. [Accessed September 28, 2012]. Available from:

16. Maiza JC, Vezzosi D, Matta M, et al. Long-term (up to 18 years) effects on GH/IGF-1 hypersecretion and tumour size of primary somatostatin analogue (SSTa) therapy in patients with GH-secreting pituitary adenoma responsive to SSTa. Clin Endocrinol (Oxf) 2007;67(2):282-289.

https://doi.org/10.1111/j.1365-2265.2007.02878.x 